University of South Florida

DIGITAL COMMONS

Digital Commons @ University of

@ UNIVERSITY OF SOUTH FLORIDA

South Florida

KIP Articles

KIP Research Publications

August 2018

\title{
Microscopic fungi on cadavers and skeletons from cave and mine environments
}

\author{
Alena Nováková \\ Alena Kubátová \\ František Sklenář \\ Vít Hubka
}

Follow this and additional works at: https://digitalcommons.usf.edu/kip_articles

\section{Recommended Citation}

Nováková, Alena; Kubátová, Alena; Sklenář, František; and Hubka, Vít, "Microscopic fungi on cadavers and skeletons from cave and mine environments" (2018). KIP Articles. 3154.

https://digitalcommons.usf.edu/kip_articles/3154

This Article is brought to you for free and open access by the KIP Research Publications at Digital Commons @ University of South Florida. It has been accepted for inclusion in KIP Articles by an authorized administrator of Digital Commons @ University of South Florida. For more information, please contact digitalcommons@usf.edu. 


\title{
Microscopic fungi on cadavers and skeletons from cave and mine environments
}

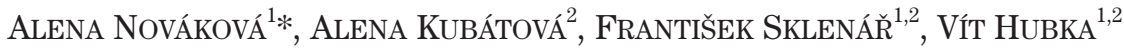 \\ ${ }^{1}$ Laboratory of Fungal Genetics and Metabolism, Institute of Microbiology of the CAS, v.v.i., \\ Vídeňská 1083, CZ-142 20 Praha 4, Czech Republic \\ ${ }^{2}$ Department of Botany, Faculty of Science, Charles University, Benátská 2, CZ-128 01 Praha 2, \\ Czech Republic \\ *corresponding author: ANmicrofungi@seznam.cz
}

Nováková A., Kubátová A., Sklenář F., Hubka V. (2018): Microscopic fungi on cadavers and skeletons from cave and mine environments. - Czech Mycol. 70(2): 101-121.

During long-term studies of microscopic fungi in 80 European caves and mine environments many cadavers and skeletons of animals inhabiting these environments and various animal visitors were found, some of them with visible microfungal growth. Direct isolation, the dilution plate method and various types of isolation media were used. The resulting spectrum of isolated fungi is presented and compared with records about their previous isolation.

Compared to former studies focused mainly on bat mycobiota, this paper contributes to a wider knowledge of fungal assemblages colonising various animal bodies in underground environments. The most interesting findings include ascocarps of Acaulium caviariforme found abundant on mammals cadavers, while Botryosporium longibrachiatum isolated from frogs, Chaetocladium jonesiae from bats and Penicillium vulpinum from spiders represent the first records of these species from cadavers or skeletons.

Key words: European caves, abandoned mines, dead bodies, bones, mammals, frogs, spiders, isopods, micromycetes.

Article history: received 11 May 2018, revised 17 June 2018, accepted 20 June 2018, published online 19 August 2018.

Nováková A., Kubátová A., Sklenář F., Hubka V. (2018): Mikroskopické houby na mrtvých tělech a kostrách živočichů v prostředí jeskyní a dolů. - Czech Mycol. 70(2): 101-121.

V průběhu dlouhodobého studia mikroskopických hub v osmdesáti evropských podzemních prostorách (jeskyně, opuštěné doly) byly nalezeny také mrtvá těla a kostry živočichů žijících v tomto prostředí či nahodilých návštěvníkủ, některé s viditelnými nárosty mikroskopických hub. Př́má izolace, zředovací metoda a různá média byly použity pro izolaci konkrétních druhů. Získané spektrum hub je prezentováno a srovnáno s předchozími nálezy.

Oproti dosavadním studiím, zaměřeným hlavně na houby napadající netopýry, je tato práce příspěvkem k širšímu poznání společenstev hub, kolonizujících těla různých živočichů v podzemním prostředí. Mezi nejzajímavější nálezy lze zařadit Acaulium caviariforme, jehož plodnice byly hojně nacházeny na mrtvých tělech savců, zatímco druhy Botryosporium longibrachiatum (izolované z žab), Chaetocladium jonesiae (z netopýrů) a také Penicillium vulpinum (z pavouků) představují první nálezy těchto druhů na mrvých tělech nebo kostrách živočichů. 


\section{INTRODUCTION}

Hitherto, the majority of studies into microfungal assemblages in underground spaces have been predominantly focused on cave air and sediments or on rock and speleothem surfaces. This seemingly nutrient-poor ecosystem can however also include many spots with organic matter, such as plant material (e.g. seeds, twigs, detritus) washed from the environment above as well as various deposits of animal inhabitants, excretions of cave-inhabiting invertebrates and vertebrates, bat droppings and guano.

Underground environments including caves are often visited by various animals which seek refuge from unfavourable weather conditions or search for food, and some of them also fall into the underground (frogs, lizards). All of these animals may die after some time as a consequence of age, food absence or collapse from exhaustion. Cadavers of cave-inhabiting animals, mainly bats, are utilised as food for caveinhabiting terrestrial invertebrates such as earthworms, isopods, diplopods, springtails, mites etc. which, together with cave microbiota, gradually decompose dead organic matter. Cadavers in various stage of decomposition are found on cave sediment or speleothems, from fresh dead bodies to skeletons or particular bones. Given the high air humidity and constant air temperature in the cave environment, successional decomposition is not limited to dry periods, as in above-ground conditions, but goes on continually. Some cadavers are covered by visible mycelia of microscopic fungi, other ones are without visible microfungal infection.

During long-term studies of cave mycobiota in various underground environments, from 2002 up to the present, mainly focused on microscopic fungi in cave air, cave sediments and bat guano, we found a number of recently deceased animals as well as skeletons and separate bones. We used various isolation techniques to elucidate which microfungal species colonise these substrates and are responsible for their decomposition. This report provides an overview of microfungal species which have been found on skeletons/bones and dead animals (with the exception of insects) inhabiting underground environments.

\section{MATERIAL AND METHODS}

Sampling sites. Studies of microfungal assemblages have been carried out since 2002, in a total of 80 underground environments of several European countries, mainly in the Czech Republic, Slovakia, Spain and Romania. Their original and English names and other characteristics are given in Tab. 1. Studied caves are karstic, oligotrophic or eutrophic, one is chemoautotrophic (Movile Cave), one is of marine origin (Treasure Cave), and two sites belong to nonkarstic environments (Na Rozhraní Cave and Simon and Jude Mines). 


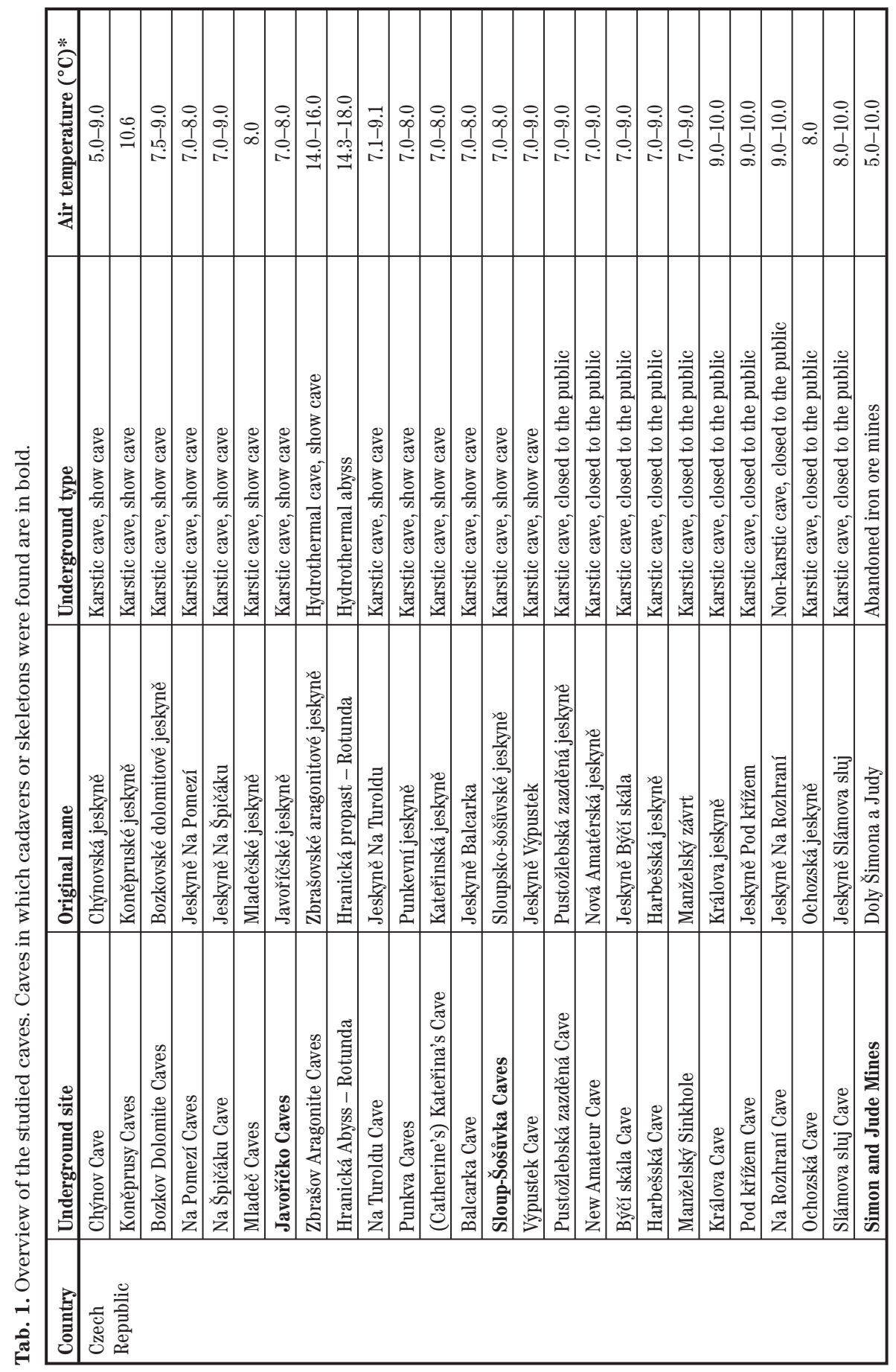




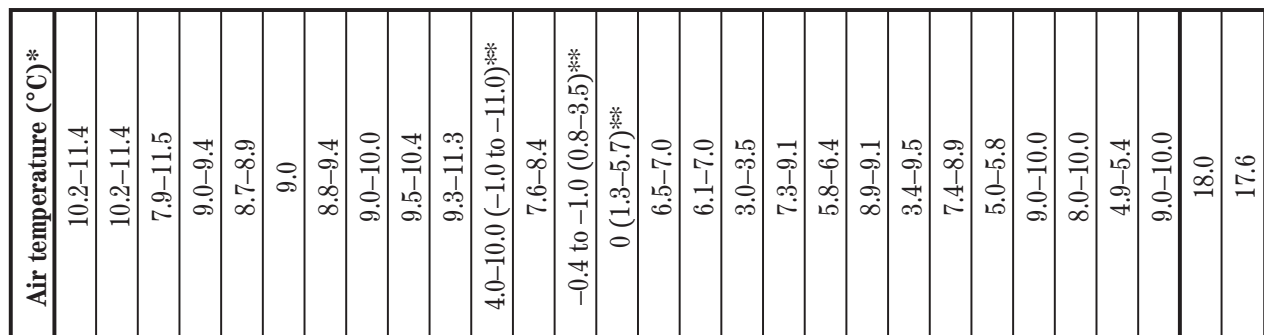

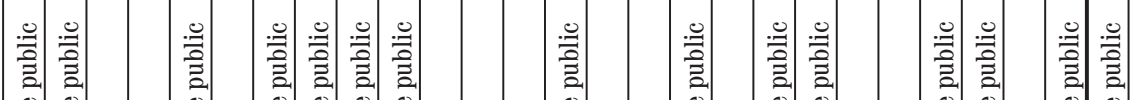

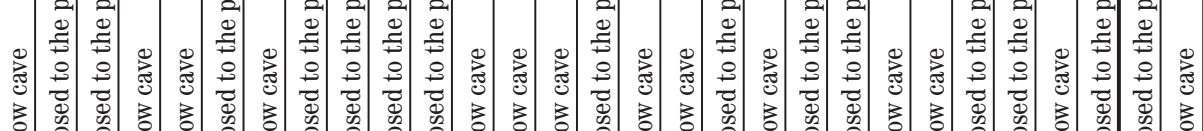

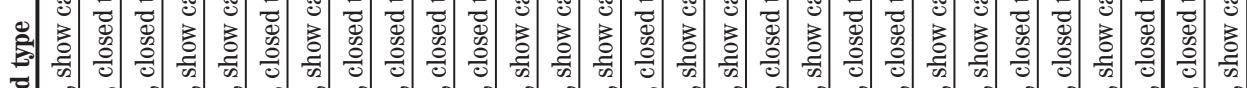

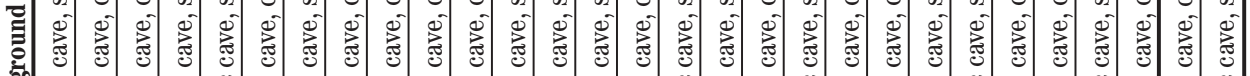

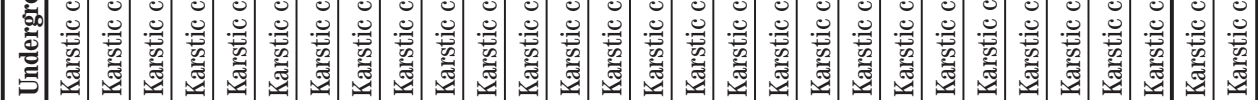

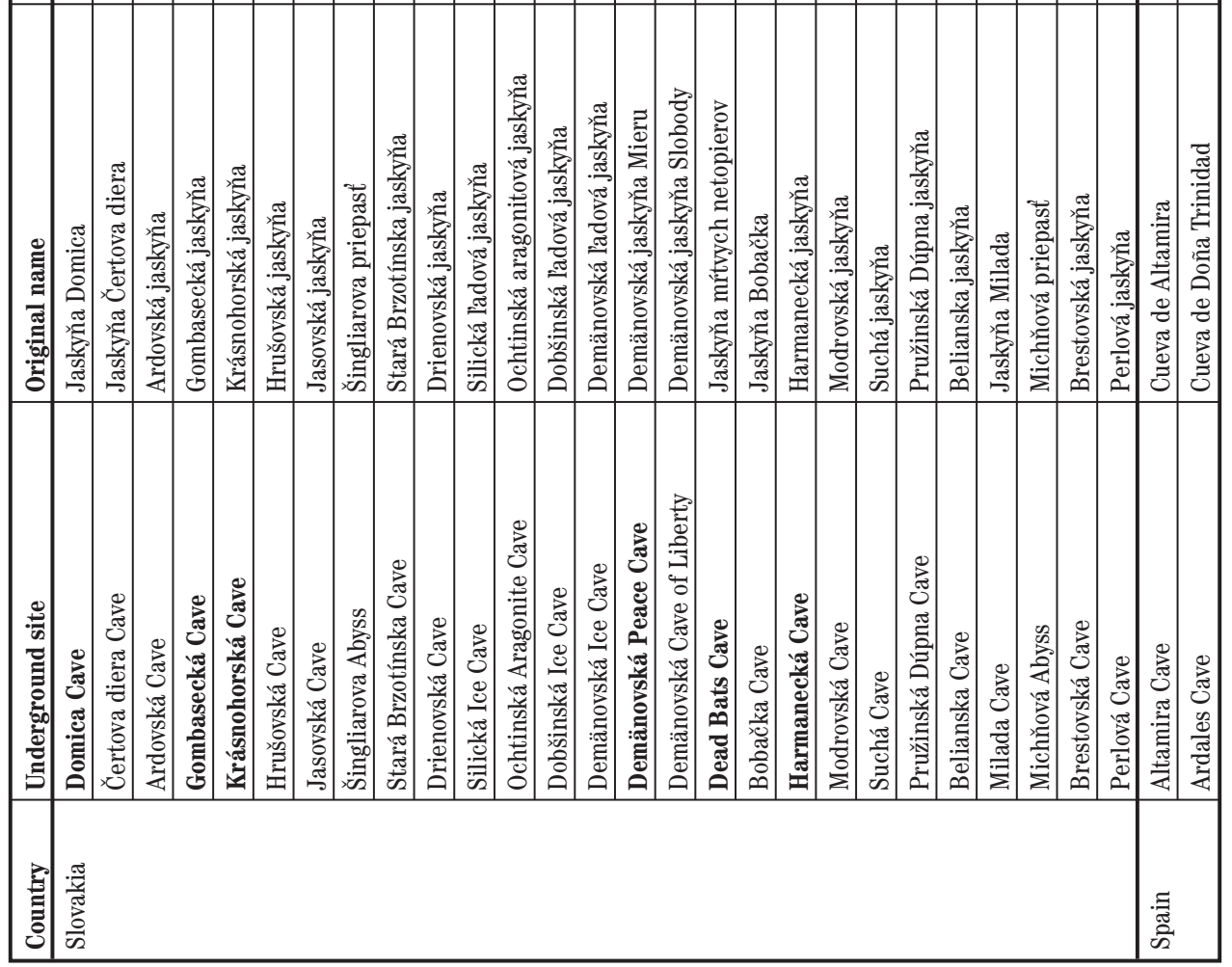




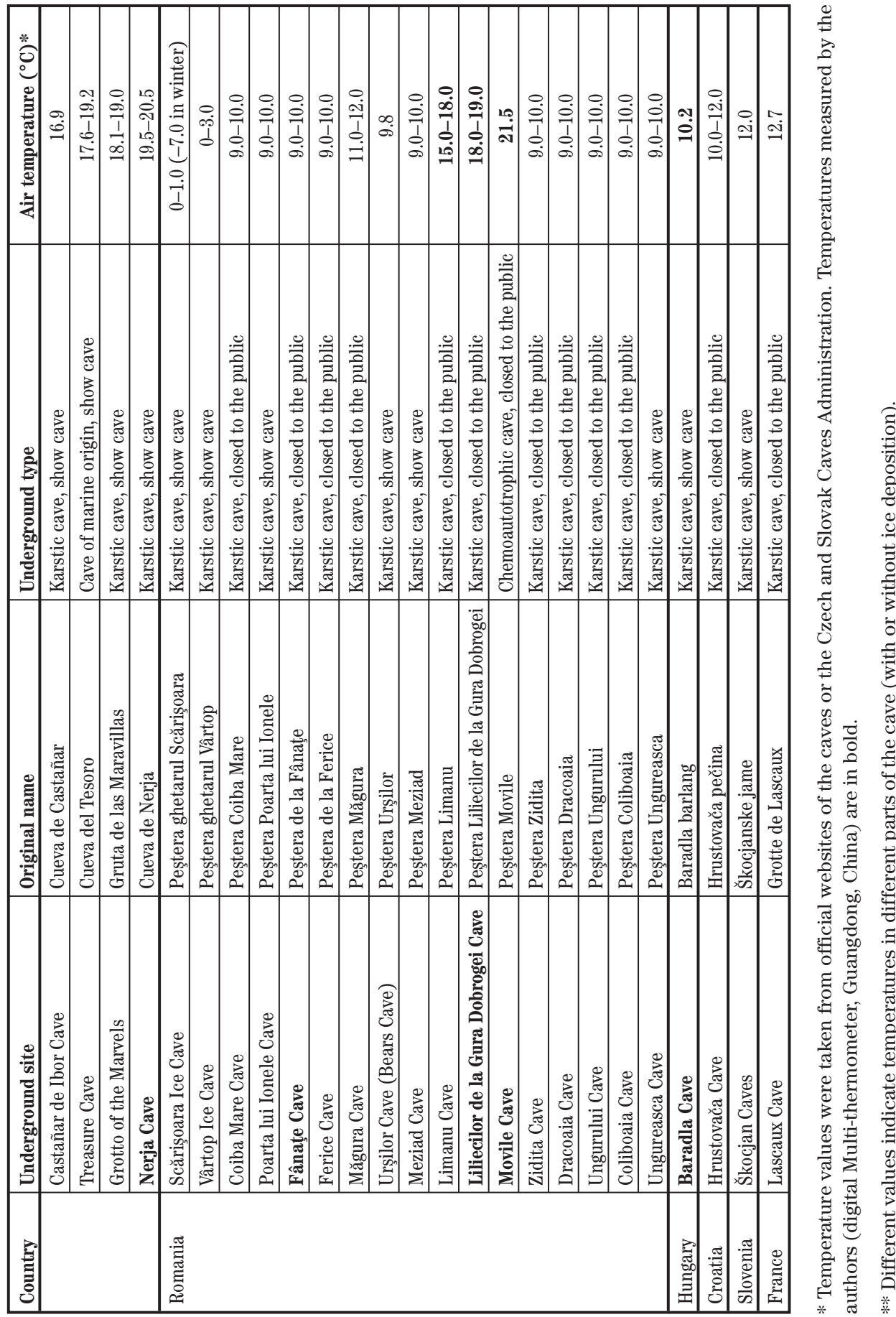


All studied sites are characterised by high air humidity (c. 98-99\%) but air temperature differed according to their geographical location as well as to cave type. While Czech, Slovak, and some Romanian caves in the Apuseni Mts. are characterised by an air temperature of 7 to $11{ }^{\circ} \mathrm{C}$, most of the studied Spanish caves and Romanian ones in the Dobrogea region are warmer cave systems with an air temperature of $16-21^{\circ} \mathrm{C}$. Some of the studied caves are abundantly inhabited by bats (e.g. the Czech Javorríčko Caves or Na Turoldu Cave, the Slovak Domica Cave, Drienovská Cave, Dead Bats Cave, Jasovská Cave, and Ardovská Cave, the Romanian Liliecilor de la Gura Dobrogei Cave, Meziad Cave, Ferice Cave and Fânaţe Cave), in others bats are less common (e.g. the Slovak Demänovská Peace Cave, Demänovská Cave of Liberty, Gombasecká Cave and Krásnohorská Cave, the Romanian Limanu Cave, the Spanish Nerja Cave, the Czech Kateřina's Cave and Sloup-Šošůvka Caves). In contrast, bats are absent from the Romanian Movile Cave, the Spanish Grotto of the Marvels, Ardales Cave, Altamira Cave, and the Slovak Ochtinská Aragonite Cave. Several caves, such as Altamira Cave, Grotto of the Marvels, and Ardales Cave (Spain), are regularly visited by various species of rodents.

Is olation and identification. Samples of cadavers - dead bodies with visible microfungal growth and degrading organic matter were collected using sterile forceps into sterile microtubes or directly on agar isolation media in Petri dishes. In the laboratory, isolations were carried out by transferring the collected material on agar discs in Petri dishes or preparing a dilution in sterile water. Dichloran rose Bengal chloramphenicol agar (DRBC), Sabouraud's glucose agar and beer wort agar, both with rose Bengal $(0.1 \mathrm{~g} / \mathrm{l})$ and chroramphenicol $(0.1 \mathrm{~g} / \mathrm{l})$ (Atlas 2010) were used as isolation media. Cultivation lasted for 7 days at $25{ }^{\circ} \mathrm{C}$ in the dark.

Microfungal identification was performed according to the macro- and micromorphological characters using relevant taxonomic literature focused on particular genera (e.g. de Hoog 2000, Samson \& Varga 2004, 2007, Samson \& Houbraken 2011, Seifert et al. 2011, Samson et al. 2011, 2013, Bensch et al. 2012, Guarro et el. 2012, Dijksterhuis et al. 2013, Hubka et al. 2016, Sandoval-Denis et al. 2016, Chen et al. 2016, 2017, etc.). Malt extract agar (MEA), Czapek yeast autolysate agar (CYA) and Czapek-Dox agar (CZA) were used for microfungal identification (Atlas 2010).

Molecular analysis. Some isolates were also identified with molecular methods. DNA was extracted from 7-day-old colonies with the ArchivePure DNA yeast and Gram2 + kit (5PRIME Inc., Gaithersburg, Maryland, USA) with modified incubation times: lytic enzyme solution $\left(2 \mathrm{~h}, 37^{\circ} \mathrm{C}\right)$ and cell lysis solution $(4 \mathrm{~h}$, $64^{\circ} \mathrm{C}$ ). Partial $c a M$ gene encoding calmodulin was amplified using forward primers CF1M or CF1L and reverse primer CF4 (Peterson 2008). The PCR mixture 
(total volume $25 \mathrm{\mu l}$ ) contained $0.1 \mathrm{\mu l} \mathrm{MyTaq}$ DNA polymerase (Bioline $\mathrm{GmbH}$, Luckenwalde, Germany), $5 \mu \mathrm{l}$ MyTaq Reaction Buffer, $1 \mu \mathrm{l}$ of each primer (10 $\mu \mathrm{M}$ stock concentration), and $1 \mu \mathrm{l}(50 \mathrm{ng})$ genomic DNA. The standard thermal cycle profile was $93{ }^{\circ} \mathrm{C}$ for $2 \mathrm{~min} ; 38$ cycles of $93{ }^{\circ} \mathrm{C}$ for $30 \mathrm{~s}, 55^{\circ} \mathrm{C}$ for $30 \mathrm{~s}, 72^{\circ} \mathrm{C}$ for $60 \mathrm{~s}$, and final extension $72{ }^{\circ} \mathrm{C}$ for $10 \mathrm{~min}$. Automated sequencing was performed at Macrogen Sequencing Service (Amsterdam, The Netherlands) using the forward and reverse primers. The obtained sequences were inspected and assembled with BioEdit version 7.1.8 (www.mbio. ncsu.edu/BioEdit/bioedit.html) and then compared with those derived from ex-type strains deposited in the GenBank database in order to identify the isolates at the species level.

Representative strains of the sequenced species are deposited in the Culture Collection of Fungi at the Department of Botany, Charles University in Prague (CCF). Obtained DNA sequences were deposited in the European Nucleotide Archive (ENA) database (Tab. 2).

Tab. 2. GenBank database accession numbers of the sequences obtained in this study.

\begin{tabular}{|l|l|l|c|c|}
\hline Species & Locality & Strain number / culture collection code* & ITS rDNA & caM \\
\hline Aspergillus aureolatus & Fânaţe Cave & S193 & LS974072 \\
\hline Aspergillus baeticus & Movile Cave & S349= CCF 5046 & LT558749 \\
\hline Aspergillus baeticus & Demänovská Peace Cave & CMF ISB 2181 = CCF 4231 & HE615119 \\
\hline Aspergillus creber & Demänovská Peace Cave & S321 & LS974073 \\
\hline Aspergillus movilensis & Movile Cave & $\begin{array}{l}\text { Mo10 CCF } 4410=\text { CMF ISB } 2614= \\
\text { NRRL } 62819=\text { CBS 134395 }\end{array}$ & HG916740 \\
\hline Aspergillus parasiticus & Harmanecká Cave & S146 & LS974074 \\
\hline Aspergillus tennesseensis & Movile Cave & S135 & LS974075 \\
\hline Aspergillus thesauricus & Movile Cave & S552 CCF 4968 & LT558753 \\
\hline Aspergillus thesauricus & Movile Cave & S741 & LS974068 \\
\hline $\begin{array}{l}\text { Botryosporium } \\
\text { longibrachiatum }\end{array}$ & $\begin{array}{l}\text { Domica-Baradla cave } \\
\text { system }\end{array}$ & CCF 5732 & LS74076 \\
\hline
\end{tabular}

* CCF - Culture Collection of Fungi, Prague; CMF - Collection of Microscopic Fungi ISB, České Budějovice; S and Mo - strains from A. Nováková's working collection.

\section{RESULTS AND DISCUSSION}

\section{Fungi on bat cadavers}

Bats belong to the most commonly known inhabitants in caves and other underground environments. Unfortunately, until recently studies were focused on the occurrence of microfungi on bat fur (Larcher et al. 2003, Beguin et al. 2005) and later mainly on Pseudogymnoascus (Geomyces) destructans as an infection agent of WNS (white nose syndrome) (Blehert et al. 2008, Gargas et al. 2009, 
Tab. 3. Overview of microfungal taxa isolated from dead animal bodies or bones.

Sites of origin: 1 - Javoříčko Caves, 2 - Sloup-Šošůvka Caves, 3 - Simon and Jude Mines, 4 - Domica Cave, 5 - Gombasecká Cave, 6 - Demänovská Peace Cave, 7 - Dead Bats Cave, 8-Harmanecká Cave, 9 -Krásnohorská Cave, 10 - Nerja Cave, 11 - Fânaţe Cave, 12 - Liliecilor de la Gura Dobrogei Cave, 13 - Movile Cave, 14 - Baradla Cave.

\begin{tabular}{|c|c|c|c|c|c|c|c|c|c|c|c|c|c|c|c|c|c|c|}
\hline Dead animals & 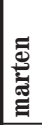 & 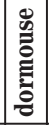 & \multicolumn{10}{|c|}{ bat } & \multicolumn{3}{|c|}{$\frac{\bar{c}}{\pi}$} & \multirow{2}{*}{ 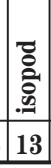 } & \multicolumn{2}{|c|}{$\stackrel{0}{\circ}$} \\
\hline Caves & 6 & 5 & 1 & 2 & 3 & 4 & 6 & 7 & 8 & 10 & 11 & 12 & 5 & 9 & 13 & & 4 & 14 \\
\hline \multicolumn{19}{|l|}{ Mucoromycota } \\
\hline Chaetocladium jonesiae (Berk. \& Broome) Fresen. & & & + & & + & & & & & & & & & & & & & \\
\hline Mortierella horticola Linnem. & & & & & & & & + & & & & & & & & & & \\
\hline Mortierella humilis Linnem. ex W. Gams & & & & + & & + & & + & & & & & & & & & & \\
\hline Mortierella sp. & & & & & & & & & & + & & + & & & & & & \\
\hline Mucor hiemalis Wehmer f. hiemalis & & & & & & & & + & & & & & & & & & & \\
\hline Mucor hiemalis f. luteus (Linnem.) Schipper & & & & + & & & & & & & & & & & & & & \\
\hline Mucor hiemalis f. silvaticus (Hagem) Schipper & & & & & & & & + & & & & & & & & & & \\
\hline Mucor mucedo P. Micheli ex St.-Amans & & & & & & & & + & & & & & & & & & & \\
\hline Mucor racemosus Fresen. var. racemosus & & & & + & & & + & + & & & & & & & & & & \\
\hline Mucor wosnessenskii Schostak. & & & & & & & + & + & & & & & & & & & & \\
\hline Rhizomucor pusillus (Lindt) Schipper & & & & & & & & + & & & & & & & & & & \\
\hline Thamnidium elegans Link & & & & + & & & & & & & & & & & & & & \\
\hline \multicolumn{19}{|l|}{ Ascomycota } \\
\hline $\begin{array}{l}\text { Acaulium caviariforme (Malloch \& Hubart) Sandoval- } \\
\text { Denis, Guarro \& Gené* }\end{array}$ & & + & & & & & + & & + & & & & & & & & & \\
\hline Aspergillus aureolatus Munt.-Cvetk. \& Bata & & & & & & & & & & & + & & & & & & & \\
\hline Aspergillus baeticus A. Nováková \& Hubka & & & & & & & + & & & & & & & & + & & & \\
\hline Aspergillus creber Jurjević, S.W. Peterson \& B.W. Horn & + & & & & & & & & & & & & & & & & & \\
\hline $\begin{array}{l}\text { Aspergillus movilensis Nováková, Hubka, M. Kolařík \& } \\
\text { S.W. Peterson }\end{array}$ & & & & & & & & & & & & & & & & + & & \\
\hline Aspergillus parasiticus Speare & & & & & & & & & + & & & & & & & & & \\
\hline Aspergillus tennesseensis Jurjević, S.W. Peterson \& B.W. Horn & & & & & & & & & & & & & & & + & & & \\
\hline Aspergillus thesauricus Hubka \& A. Nováková & & & & & & & & & & & & & & & & + & & \\
\hline Botryosporium longibrachiatum (Oudem.) Maire & & & & & & & & & & & & & & & & & + & + \\
\hline Cephalotrichum stemonitis (Pers.) Nees & & & & & & & + & & & & & & & & & & & \\
\hline Chrysosporium sp. & & & & & & & & + & & & & & & & & & & \\
\hline Cladosporium cladosporioides (Fresen.) G.A. de Vries & & & & & & & + & & & & & & & & & & & \\
\hline Cladosporium herbarum (Pers.) Link & & & & & & & & + & & & & & & & & & & \\
\hline Cladosporium sphaerospermum Penz. & & & & & & & & + & & & & & & & & & & \\
\hline Cylindrocarpon obtusiusculum (Sacc.) U. Braun & & & & & & & + & & & & & & & & & & & \\
\hline Fusarium merismoides Corda & & & & & & & + & & & & & & & & & & & \\
\hline Gliomastix chartarum (Corda) S. Hughes & & & & & & & & + & & & & & & & & & & \\
\hline Oidiodendron griseum Robak & & & & & & & + & + & & & & & & & & & & \\
\hline Penicillium aurantiogriseum Dierckx & & & & & & & + & & & & & & & & & & & \\
\hline
\end{tabular}


Nováková A., Kubátová A., Sklenář F., HubKa V.: Microscopic Fungi on CAdAVERS

\begin{tabular}{|c|c|c|c|c|c|c|c|c|c|c|c|c|c|c|c|c|c|c|}
\hline Dead animals & 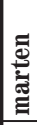 & 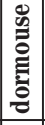 & \multicolumn{10}{|c|}{ bat } & \multicolumn{3}{|c|}{ 离 } & \multicolumn{3}{|c|}{\begin{tabular}{l|l|l} 
& \\
0 & 0 \\
\end{tabular}} \\
\hline Caves & 6 & 5 & 1 & 2 & 3 & 4 & 6 & 7 & 8 & 10 & 11 & 12 & 5 & \begin{tabular}{l|lll}
9 & 1 & & \\
1
\end{tabular} & $13 \mid 1$ & $13 \mid 4$ & $4 \quad 1$ & 14 \\
\hline Penicillium chrysogenum Thom & & & & & & & + & & & & & & & & & & & \\
\hline Penicillium corylophilum Dierckx & & & & & & & + & & & & & & & & & & & \\
\hline Penicillium olsonii Bainier \& Sartory & & & & & & & & + & & & & & & & & & & \\
\hline Penicillium vulpinum (Cooke \& Massee) Seifert \& Samson & & & & & & & & & & & & & + & + & & & & \\
\hline Pseudogymnoascus pannorum complex & & & & & & & + & & & & & & & & & & & \\
\hline Undetermined strains & & & & & & & & & & & & & & & & & & \\
\hline Sterile dark pigmented mycelium & & & & & & & & + & & & & & & & & & & \\
\hline Undetermined yeast & & & & & & & + & & & & & & & & & & & \\
\hline Undetermined basidiomycetes & & & & & & & & + & & & & & & & & & & \\
\hline
\end{tabular}

* The identification was carried out only on microscopic features of collected material, not isolated.

Martínková et al. 2010, Wibbelt et al. 2010, Puechmaille et al. 2011, Johnson et al. 2013, Zukal et al. 2014, Vanderwolf et al. 2016 etc.) and microfungal colonisation of bat cadavers was neglected.

At the place of their roosting or hibernation as well as in places where they move through, their cadavers can be found in various stages of decomposition and with progressive microfungal colonisation. Bat cadavers with white cottony overgrowth (mostly of Myotis myotis, but in some case unidentifiable due to disintegration) were found in several caves during 2005-2011, e.g. Domica Cave, Dobšinská Ice Cave and Dead Bats Cave (Slovakia), Nerja Cave (Spain), and Liliecilor de la Gura Dobrogei Cave (Romania) (Fig. 1a-c). From all these cadavers, non-sporulating strains of the genus Mortierella were isolated, which were identified on the genus level according to their characteristic colony growth (typical lobate colonies) and garlic odour. A hanging dead bat (Myotis myotis) with white mycelial overgrowth (Fig. 1d) identified according to its macro- and micromorphological properties as Mortierella humilis (Fig. 1f-g) was found in Sloup-Šošůvka Caves (Moravian Karst, Czech Republic). This species was also isolated from fine mycelium growing on bat bones (Fig. 1e) on display in the Dead Bats Cave (Slovakia). Aspergillus aureolatus was isolated from bat cadavers found in the entrance corridor of the Liliecilor de la Gura Dobrogei Cave in Romania. During our sampling in galleries of the Simon and Jude Mines near the village of Malá Morávka (northern Moravia, Czech Republic) in spring 2015 we found several fresh bat cadavers. These bats had been killed by marten (Martes foina), after which their cadavers in an early stage of decomposition were colonised by predominantly zygomycetous fungi (Fig. 2), especially by Mucor spp. and Chaetocladium jonesiae. Chaetocladium sp. was also found on a bat cadaver collected in Javoříčko Caves (Czech Republic). Species of the genus 

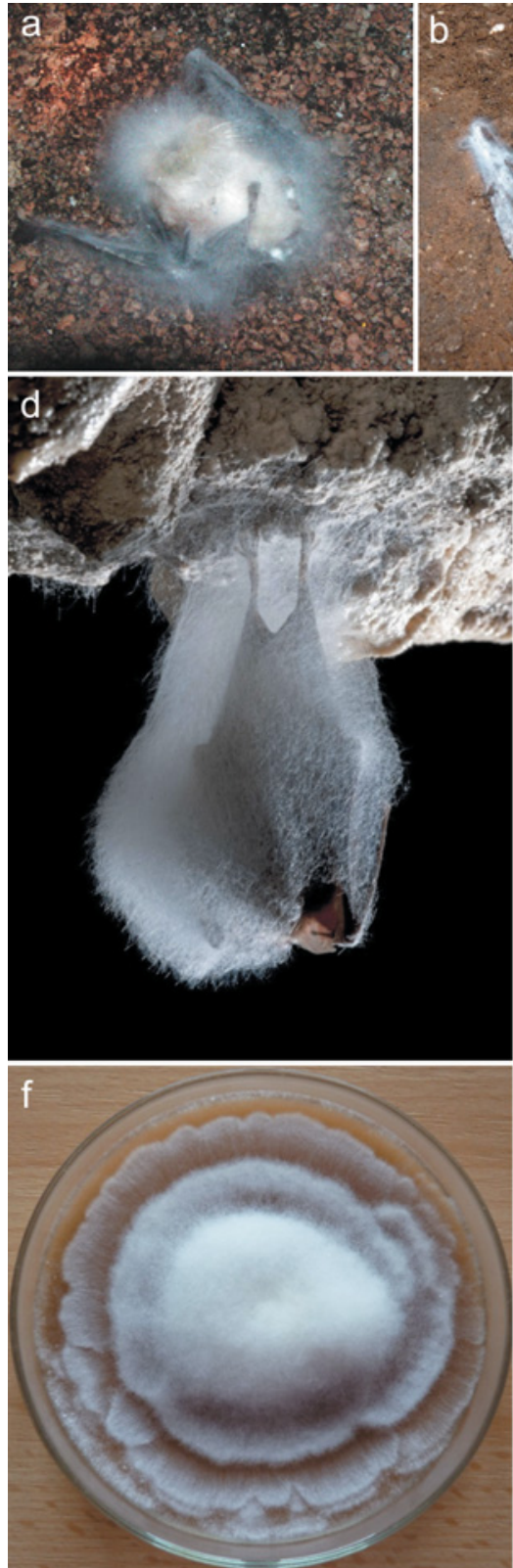
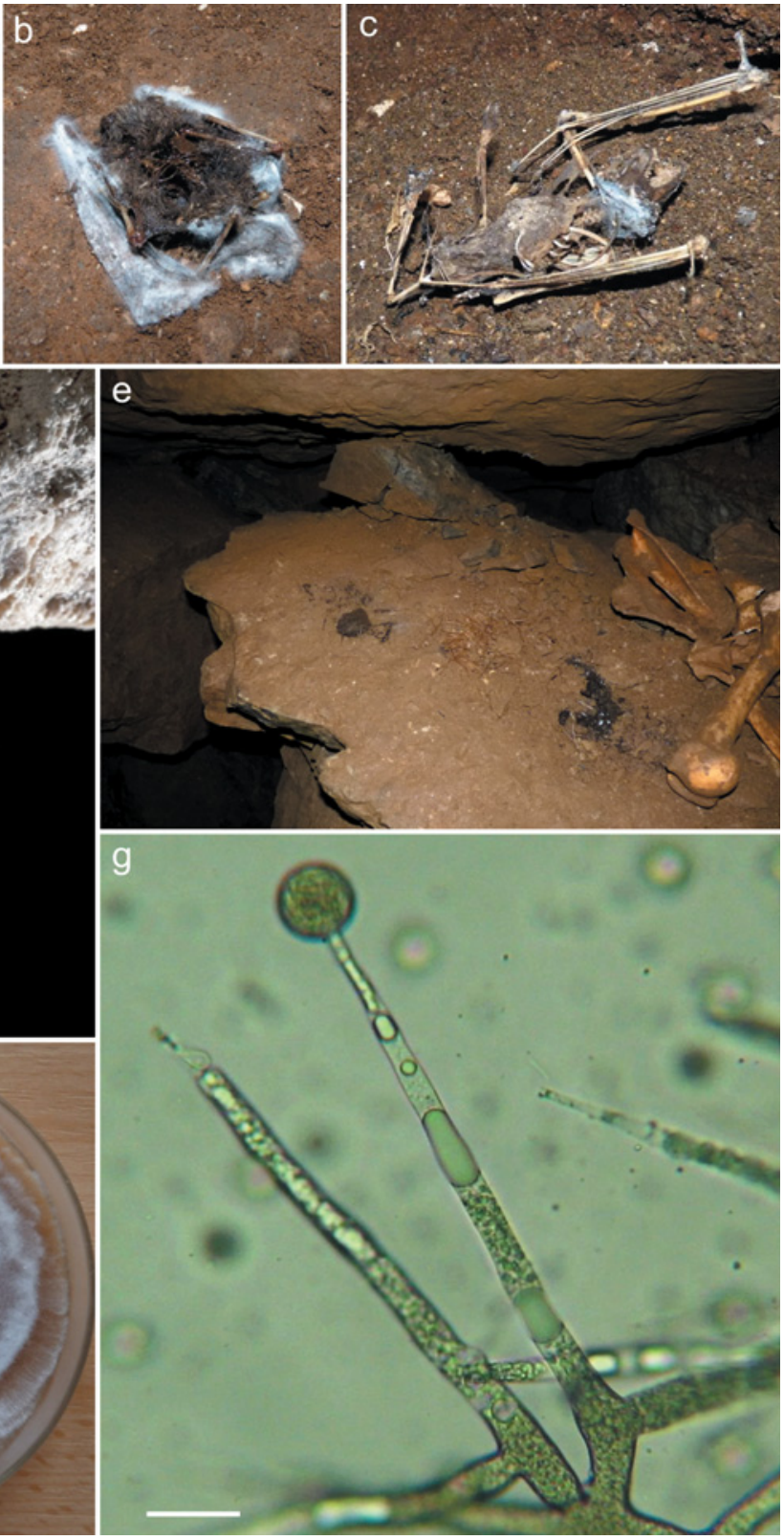

Fig. 1. Mortierella spp. on dead bat bodies. a - Domica Cave (Slovakia); b - Nerja Cave (Spain); c-Liliecilor de la Gura Dobrogei Cave (Romania); d - growth of Mortierella humilis on dead Myotis myotis (Sloup-Šošůvka Caves, Czech Republic); e - exhibition of bones in Dead Bats Cave (Slovakia); f - 14-day old colony of $M$. humilis on malt extract agar; $\mathbf{g}-$ M. humilis, sporangiophore with young sporangium. Scale bar $=20 \mu \mathrm{m}$. Photo A. Nováková (a-c, e-g), P. Zajíček (d). 

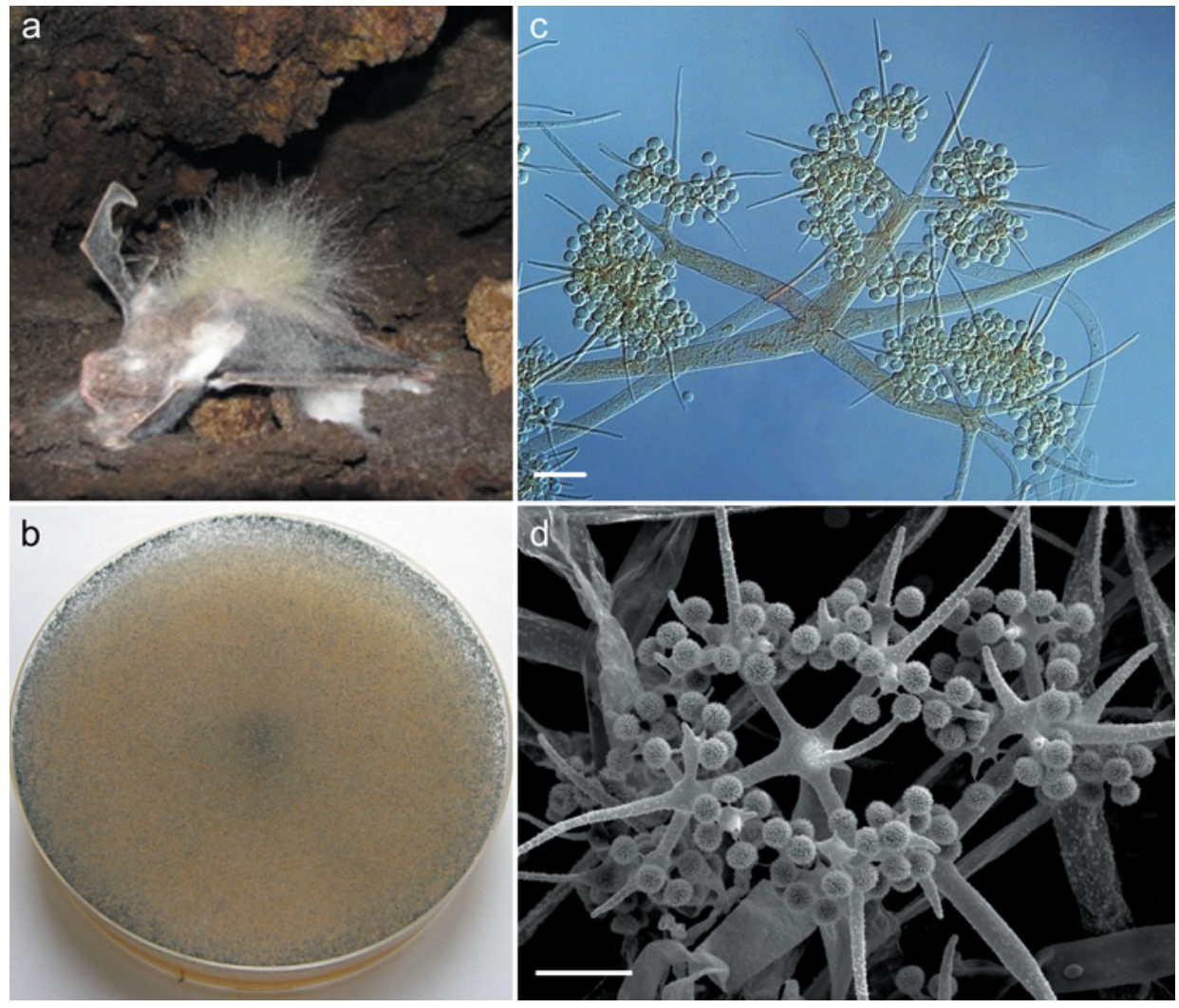

Fig. 2. Chaetocladium jonesiae. a - colonies on dead bats in Simon and Jude Mines, Malá Morávka (Czech Republic); b - 10-day old colony on MEA; c, d - branched fertile hyphae with unispored sporangia and sterile spines (c-Nomarski interference contrast, $d-S E M)$. Scale bars $=20 \mu \mathrm{m}$. Photo A. Kubátová.

Chaetocladium mainly belong to facultative, gall-forming parasites on other Mucorales (Benny 2005) and strains of this genus were earlier isolated from marten dung in Ardovská Cave as well as from cave sediment of the Domica Cave (Nováková, unpublished).

On the contrary, older bat cadavers found in Demänovská Peace Cave and Harmanecká Cave (Fig. 3) as well as dormouse cadavers found in Gombasecká Cave (Slovak Karst, Slovakia) were found to be covered by a mass of black ascocarps of Acaulium caviariforme. The isolation of this species was unsuccessful but its typical morphology enabled reliable identification. In the case of two dormouse (Dryomys nitedula) cadavers found in Gombasecká Cave after summer floods, we could observe a fungal succession on dead bodies: the occurrence of zygomycetous fungi (Mucor spp. and Mortierella spp. in an early stage) was fol- 

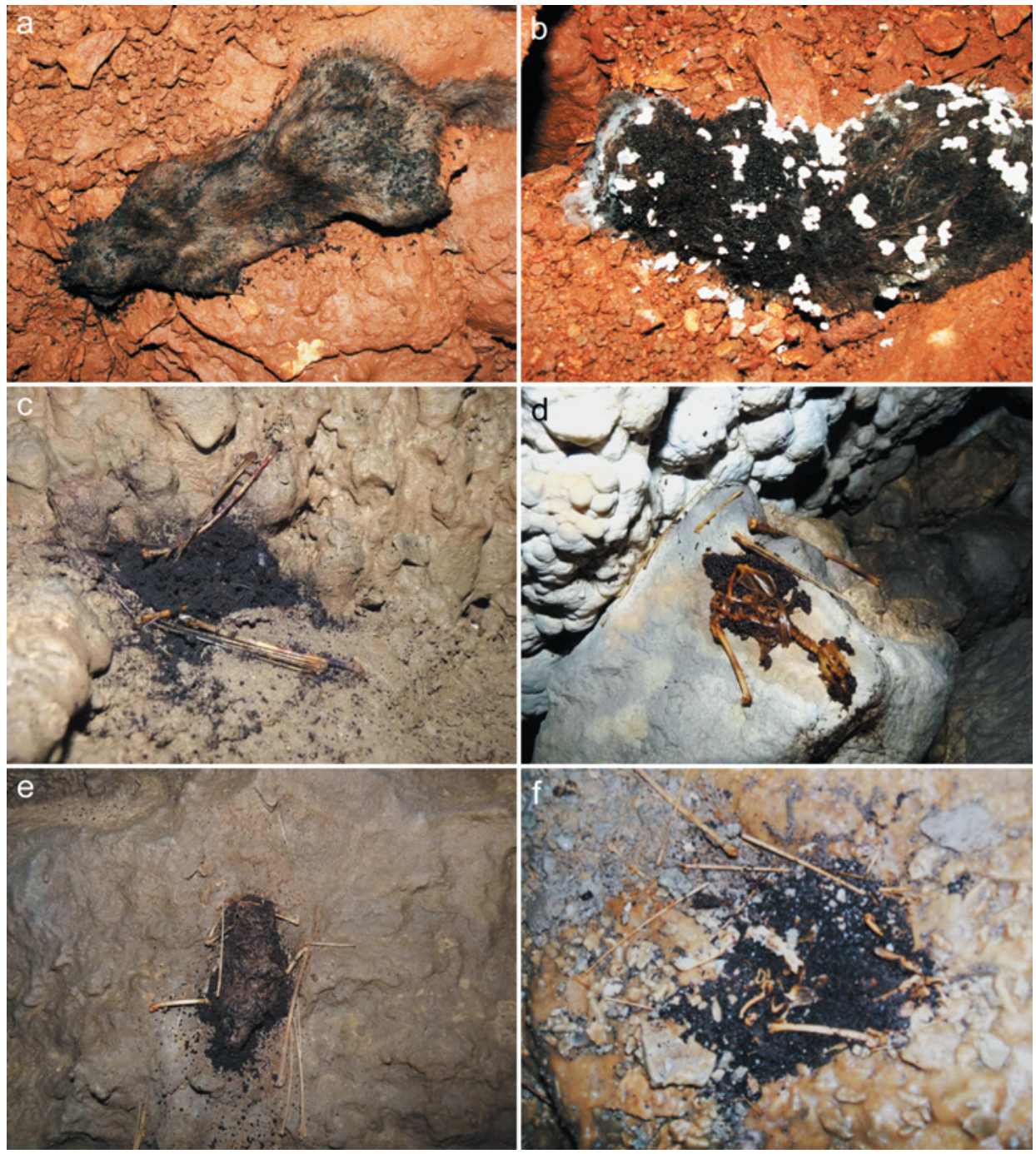

Fig. 3. Acaulium caviariforme $\mathbf{a}$ - black ascocarps on dead dormouse body; $\mathbf{b}$ - detail of dead dormouse body with black ascocarps of $A$. caviariforme and white Mortierella sp. growth; c-f - a mass of black ascocarps on bat skeletons from Slovak caves: Guličková Passage in Demänovská Peace Cave (c, d), Ruins Passage in Demänovská Peace Cave (e), Stray Dome in Harmanecká Cave (f). Photo A. Nováková.

lowed by large numbers of ascocarps of Acaulium caviariforme after several months. This fungus was first found in the Cave of Ramioul (Belgium) and described as Microascus caviariformis (Malloch \& Hubart 1987) and recently transferred to the genus Acaulium (Sandoval-Denis et al. 2016). Vanderwolf et al. 

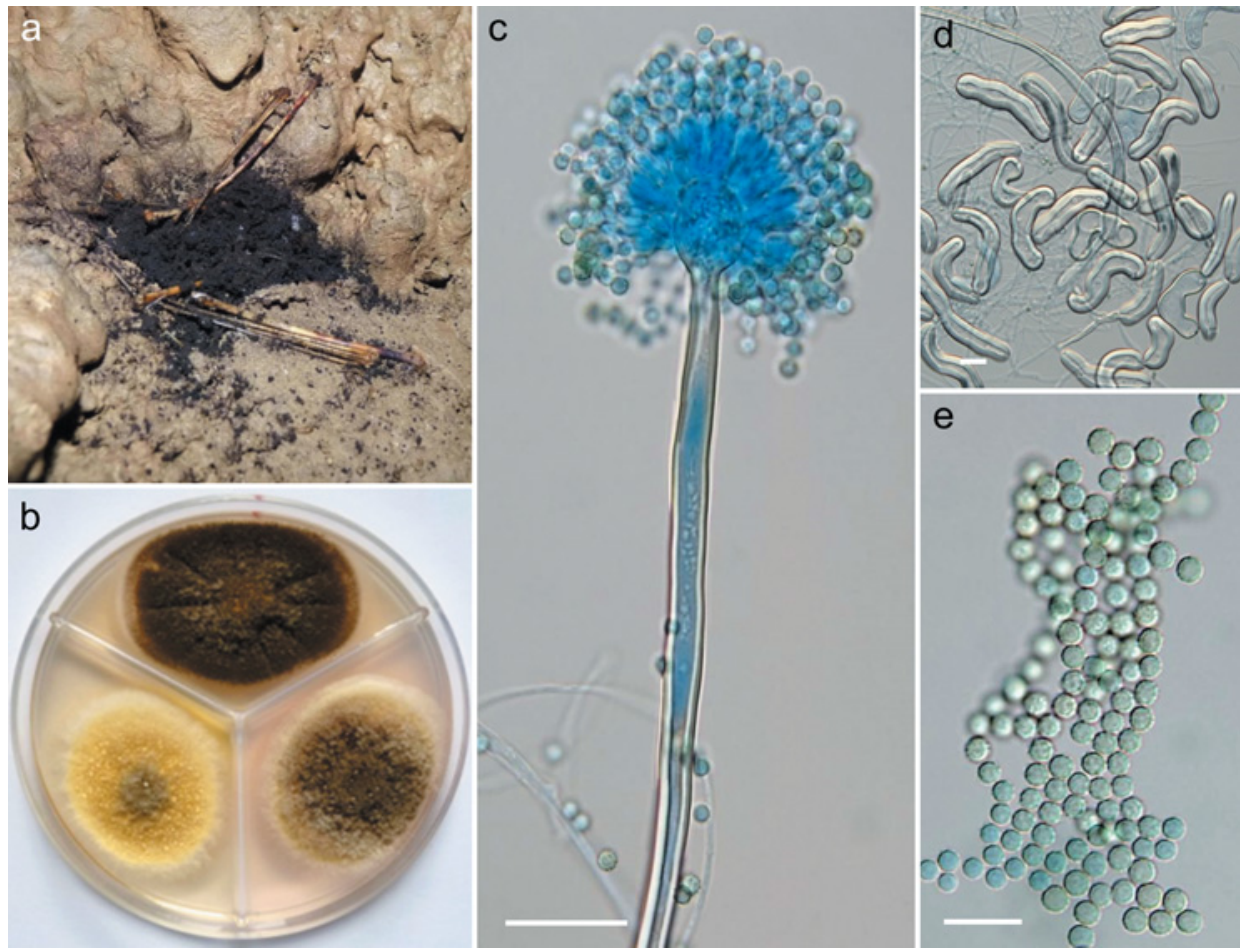

Fig. 4. Aspergillus baeticus. a - bat skeleton with a mass of black material from which this species was isolated (Guličková Passage in Demänovská Peace Cave, Slovakia); b - 7-day old colonies on CYA (top), MEA (bottom left) and CZA (bottom right); c - conidiophore; d - Hülle cells; e - conidia. Scale bars = $20 \mu \mathrm{m}(\mathrm{c}, \mathrm{d}), 10 \mu \mathrm{m}(\mathrm{e})$. Photo A. Nováková (a, b), A. Kubátová (c-e).

(2013a) isolated this species from fur of hibernating bats in three New Brunswick caves, Canada. The occurrence of $A$. caviariforme ascomata on bat carcasses in an advanced stage of decomposition, just consisting of remnant fur and bone, was observed in the New Brunswick hibernacula (Vanderwolf et al. 2016a). In spite of the fact that this species has been rarely reported from underground environments, it is probably a common microfungal species participating in the decomposition of dead animals in caves and mines.

Using the dilution isolation method (Garrett 1981), several filamentous fungi were isolated during our surveys (Tab. 3). Aspergillus baeticus, Cephalotrichum stemonitis, Cylindrocarpon obtusiusculum, Fusarium merismoides, Mucor racemosus var. racemosus, Mucor wosnessenskii, Oidiodendron griseum and Pseudogymnoascus pannorum s.l. were isolated from dead bats collected in the Demänovská Peace Cave. Aspergillus baeticus (Fig. 4) had already been isolated from Spanish Treasure Cave, Grotto of the Marvels (Nováková et al. 2012) and 
Tab. 4. An overview of microfungal taxa isolated from dead bats, reported in previous studies.

\begin{tabular}{|c|c|c|}
\hline References & Country & Species \\
\hline Zeller (1966) & Hungary & Chrysosporium merdarium \\
\hline $\begin{array}{l}\text { Wibbelt } \\
\text { et al. }(2010)\end{array}$ & \begin{tabular}{|l|} 
United \\
Kingdom \\
\end{tabular} & Penicillium sp. \\
\hline $\begin{array}{l}\text { Voyron } \\
\text { et al. (2011) }\end{array}$ & Italy & $\begin{array}{l}\text { Alternaria sp., Aspergillus sp., Candida palmioleophila, Chrysosporium/Gymnoascus, } \\
\text { Chrysosporium merdarium, Cladosporium cladosporioides, Fusarium dimerum, Fusarium } \\
\text { equiseti, Gymnoascaceae, Lecanicillium lecanii, Mortierella gamsii, Mortierella polycephala, } \\
\text { Mucor hiemalis } \text { f. hiemalis, Mucor plumbeus, Mucor racemosus, Ophiostomataceae, } \\
\text { Penicillium griseofulvum, Penicillium } \text { sp., Thielavia } \text { sp., Trichosporon chiropterorum }\end{array}$ \\
\hline $\begin{array}{l}\text { Nováková } \\
\text { (2012) }\end{array}$ & Slovakia & Mortierella humilis \\
\hline $\begin{array}{l}\text { Vanderwolf } \\
\text { et al. }(2013 \mathrm{~b})\end{array}$ & world & $\begin{array}{l}\text { Acremonium implicatum, Alternaria } \mathrm{sp} ., \text { Arthroderma silverae, Aspergillus baeticus, } \\
\text { Aspergillus sp., Candida palmioleophila, Chrysosporium merdarium, Chrysosporium sp., } \\
\text { Cladosporium cladosporioides, Clonostachys rosea f. catenulata, Fusarium dimerum, } \\
\text { Fusarium equiseti, Gliocladium atrum, Gymnoascus } \text { sp., Gymnoascaceae unidentified, } \\
\text { Lecanicillium lecanii, Mortierella gamsii, Mortierella polycephala, Mucor hiemalis } \\
\text { f. hiemalis, Mucor piriformis, Mucor plumbeus, Mucor racemosus, Ochroconis constricta, } \\
\text { Ophiostomataceae unidentified, Penicillium glandicola, Penicillium restrictum, Penicillium } \\
\text { sp., Scolecobasidium tenerum, Sporobolomyces pruinosum, Thielavia terricola, Thielavia } \text { sp., } \\
\text { Trichosporon chiropterorum }\end{array}$ \\
\hline $\begin{array}{l}\text { Vanderwolf } \\
\text { et al. (2016) }\end{array}$ & Canada & $\begin{array}{l}\text { Acaulium caviariforme, Acremonium spp., Arachniotus sp., Arthroderma silverae, } \\
\text { Cephalotrichum stemonitis, Chrysosporium merdarium, Chrysosporium sp., Fusarium sp., } \\
\text { Leuconeurospora capsici, Mortierella } \text { sp., Mucor sp., Oidiodendron truncatum, } \\
\text { Pseudogymnoascus destructans, Pseudogymnoascus pannorum s.l., Trichoderma sp., } \\
\text { Trichosporon dulcitum }\end{array}$ \\
\hline
\end{tabular}

Nerja Cave (Nováková, unpublished) and was later isolated from the Romanian Movile Cave (Nováková et al. 2018). Aspergillus parasiticus, Gliomastix chartarum, Mortierella humilis, M. horticola, Mucor hiemalis var. hiemalis, M. hiemalis var. silvaticus, M. mucedo, M. wosnessenskii, Cladosporium herbarum s.l., Rhizomucor pusillus and a sterile dark pigmented fungus were isolated from a dead bat collected in Harmanecká Cave and Clonostachys rosea f. rosea, Mortierella sp. and Mucor mucedo were isolated from dead dormouse bodies found in the Gombasecká Cave.

Previously published records of micromycetes including yeasts isolated from dead bats in underground environments are given in Tab. 4. A total of 48 fungal species were isolated from bat cadavers. Twenty microfungal taxa are reported in the study on dead bats in the Grotta del Palummaro located in southern Italy and in the Grotta delle Vene, Piedmont, Italy (Voyron et al. 2011), while 16 microfungal species were isolated from dead bats in New Brunswick hibernacula (Vanderwolf et al. 2016). A world review of Canadian researchers (Vanderwolf et al. 2013b) reported a survey of published records of fungi, yeasts and slime 


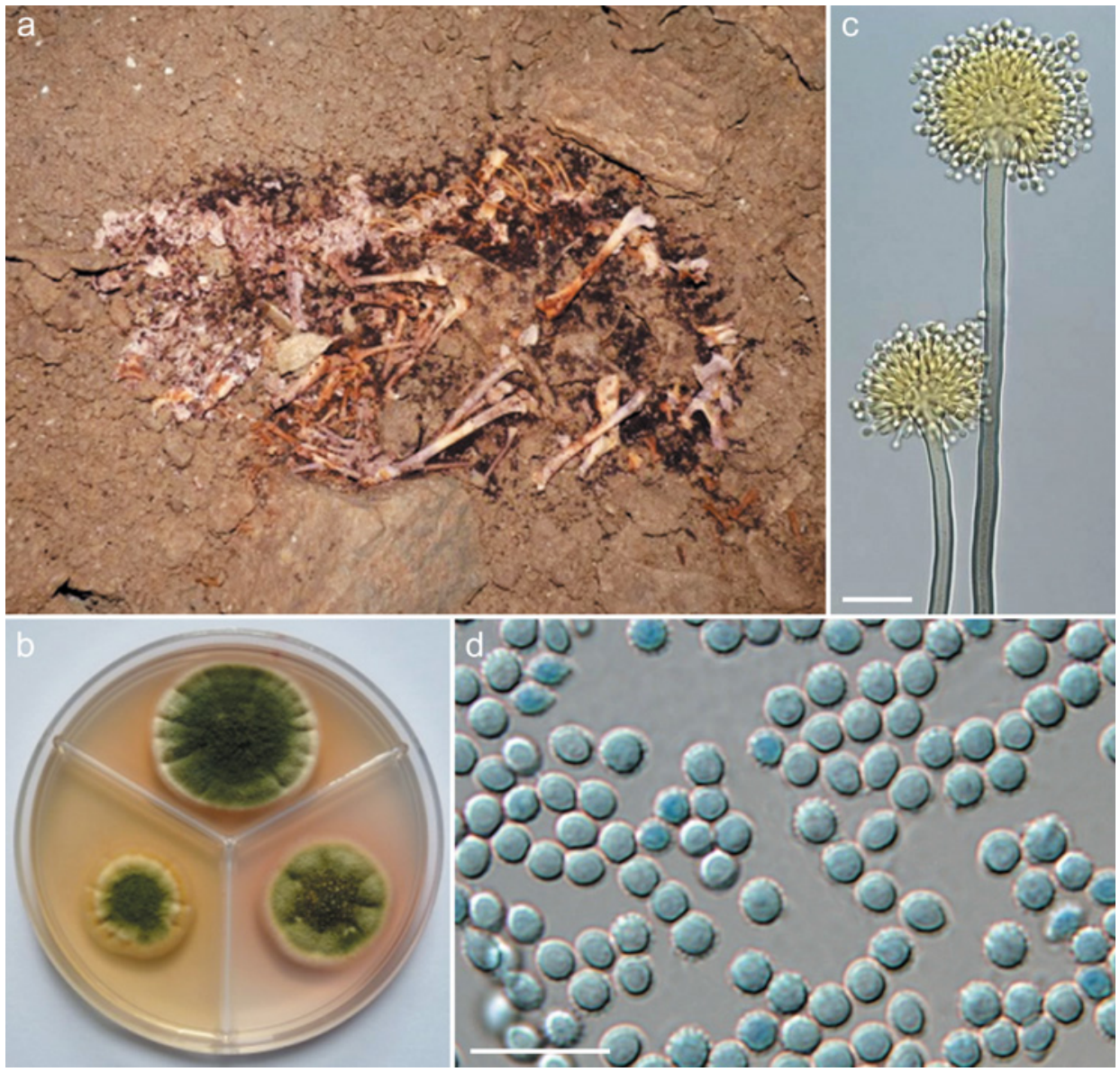

Fig. 5. Aspergillus creber. a - marten skeleton in Guličková Passage, Demänovská Peace Cave (Slovakia) from which the species was isolated; b - 7-day old colonies on CYA (top), MEA (bottom left) and CZA (bottom right); c - conidiophore; $\mathbf{d}$ - conidia. Scale bars = $20 \mu \mathrm{m}$ (c), $10 \mu \mathrm{m}$ (d). Photo A. Nováková (a, b), A. Kubátová (c, d).

moulds in caves including 32 microfungal species isolated from bat cadavers. On the contrary, Zeller (1966) and Wibbelt et al. (2010) presented only one isolated species. The most frequently reported species from dead bats is Chrysosporium merdarium. Nováková (2009) isolated a species identified as Mortierella humilis only once (Nováková 2012).

Our records are rather poor in comparison with the results of studies by Voyron et al. (2011) and Vanderwolf et al. (2016) only targeted at mycobiota of dead bats, because they originate from random finds during studies focused on 
Czech Mycology 70(2): 101-121, August 19, 2018 (ONLINE VERSION, ISSN 1805-1421)

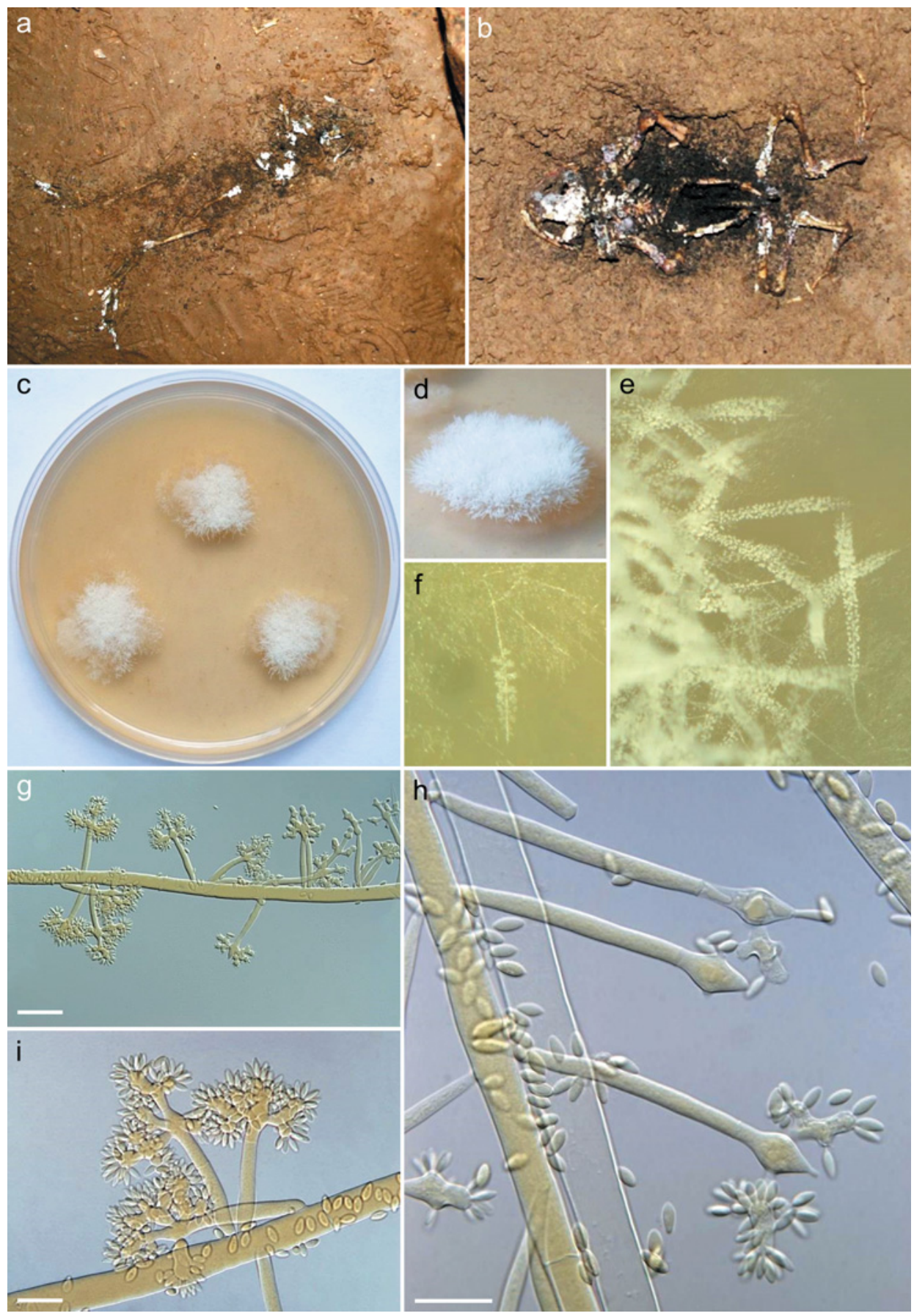



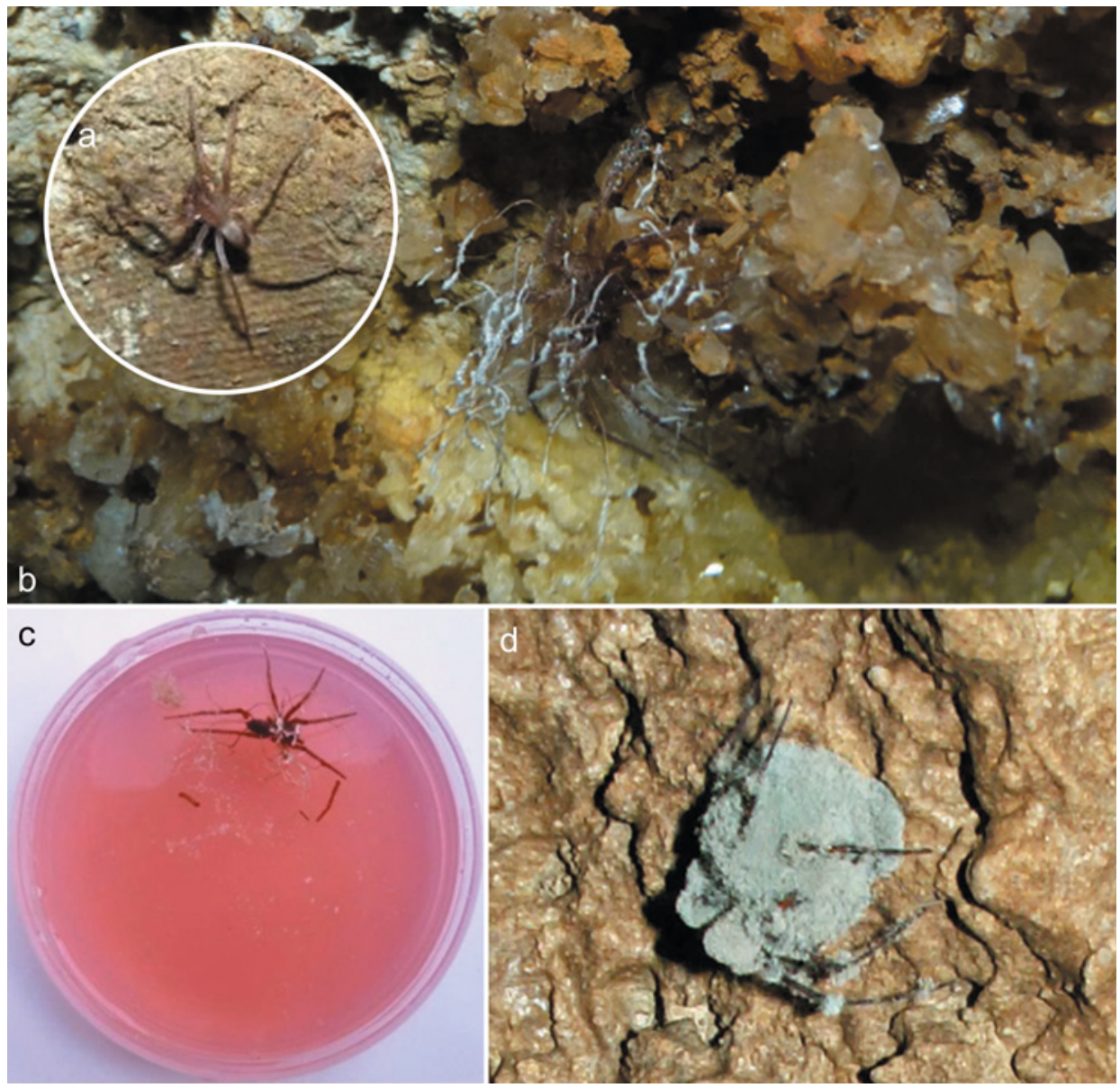

Fig. 7. Spiders. a - Agraecina cristianii; b - dead A. cristianii with synnematal microfungal growth, cave wall (Lake Room, Movile Cave, Romania); c - collected sample on Petri dish with DRBC; $\mathbf{d}$ - colonies of Penicillium vulpinum on dead spider body (Meta menardi) in entrance corridor of Krásnohorská Cave (Slovakia). Photo A. Nováková.

4 Fig. 6. Botryosporium longibrachiatum. a, b-frog skeletons with visible white growth (DomicaBaradla cave system, Slovakia); c, d - 14-day old colonies of B. longibrachiatum on MEA; e, f - detail of colony margin with visible conidiophores; g-i - conidiophore details: branches with conidiogenous cells and conidia. Scale bars = $50 \mu \mathrm{m}(\mathrm{g}), 20 \mu \mathrm{m}(\mathrm{h}, \mathrm{i})$. Photo A. Nováková (a-f), A. Kubátová (g-i).

cave mycobiota including fungal occurrence in cave air, sediments, bat guano, and animal excretions. Nevertheless, some of our records are very interesting and include rarely isolated species and first reports from this substrate. 


\section{Fungi on other animals}

Underground environments are also visited by other animals, e.g. martens (Martes foina), dormice (Dryomys nitedula), frogs (Pelophylax sp.), and spiders (Meta menardi in entrance sections but also some true cave-inhabitants such as the endemic Agraecina cristianii in Movile Cave). Besides the abovementioned dormice, martens are very frequent visitors to caves and abandoned mines. Some of them enter underground sites to protect themselves from bad weather conditions or in order to search for food. Therefore marten cadavers or skeletons were also occasionally found in caves - e.g. a well-preserved marten skeleton was found in the Guličková Passage of the Demänovská Peace Cave (Fig. 5). Bones lacked visible microfungal growth, but cultivation yielded Aspergillus creber (identified using the caM gene, see Tab. 2).

Other animals such as frogs and lizards visit cave environments occasionally after summer floods or storms, because of downfall or during searching for a colder site during a hot summer. Their long-term stay in the underground mostly ends in death because of starvation. Frog skeletons with visible white microfungal growth identified as Botryosporium longibrachiatum were discovered in the Domica-Baradla cave system (Fig. 6). Our find is the first record of this fungus from an animal substrate as well as from a cave environment. Thus far, this species had been recorded predominantly from plant material including Curcuma rubricaulis leaves (Tribe \& Weber 2001) and later from a wide variety of dead and decaying plant material (Tribe \& Weber 2001, Park \& Park 2013) or as an airborne species (Anonymus 2016).

During our study of the mycobiota of the Movile Cave (Romania), we isolated microscopic fungi from dead invertebrate bodies. Several species of the genus Aspergillus were isolated from a dead endemic spider, Agraecina cristianii, i.e. Aspergillus baeticus and A. tennesseensis, whilst A. movilensis and A. thesauricus were isolated from a dead diplopod, Trachelipus troglobius (Nováková et al. 2018).

Synnematal microfungal colonies (Fig. 7b) were found on some cadavers of the spider Agraecina cristianii in the Lake Room of Movile Cave in 2013. It was impossible to identify this fungus based on morphological characters and isolation was unsuccessful. Unfortunately, similar dead spider bodies with synnematal colonies were not found during sampling in the following years. Dead spider bodies (Meta menardi) were also found in Gombasecká Cave and Krásnohorská Cave (Slovak Karst) (Fig. 7d) and in both cases, Penicillium vulpinum was isolated from them. This species is a coprophilous fungus frequently found in caves on various sorts of dung. 


\section{CONCLUSIONS}

During our studies, a total of 39 fungal taxa (classified as species, forms or identified at a supraspecific level) on various cadavers and skeletons found in underground environment were identified in several European caves and mines. Thirtyeight species were isolated in pure cultures - 12 of them belonging to Mucoromycota, 23 species to Ascomycota, while 3 strains were not identified to the species level. Species of the genera Mucor and Aspergillus were isolated most abundantly. The richest microfungal spectrum was found in the Demänovská Peace Cave and Dead Bats Cave, from which 14 and 16 microfungal species were isolated, respectively. The ascomycete Acaulium caviariforme was reported repeatedly from several Slovak caves, but unfortunately the isolation of these strains failed. However, this fungus is probably a common fungal species participating in the decomposition process of dead animals in underground environments.

\section{ACKNOWLEDGEMENTS}

We thank Milada Chudíčková and Alena Gabrielová (Institute of Microbiology of the CAS, Prague) and Ivana Borovičková (Department of Botany, Charles University, Prague) for their invaluable assistance in the laboratory.

\section{REFERENCES}

ANONYMUS (2016): Botryosporium longibrachiatum. -

http://www.mycobank.org/BioloMICS.aspx?Table=Mycobank\&Rec=3319\&Fields=All. [accessed May 2018]

ATLAS R.M. (2010): Handbook of microbiological media. - CRC Press, Washington, D.C.

Beguin H., LARCHER G., NOLARD N., CHABASSE D. (2005): Chrysosporium chiropterorum sp. nov., isolated in France, resembling Chrysosporium state of Ajellomyces capsulatus (Histoplasma capsulatum). - Medical Mycology 43(2): 161-169.

BENNY G.L. (2005): Chaetocladium. - http://zygomycetes.org/index.php?id=102. [accessed May 2018] Bensch K., Braun U., Groenewald J.Z., Crous P.W. (2012): The genus Cladosporium. - Studies in Mycology 72: 1-401.

Blehert D.S., Hicks A.C., Behr M., Meterer C.U., Berlowski-ZiER B.M., BuCKLes E.L., Coleman J.T., DARling S.R., Gargas A., Niver R., OKOniewski J.C., RudD R.J., STONE W.B. (2008): Bat whitenose syndrome: an emerging fungal pathogen? - Science 323(5911): 227.

Chen A.J., Frisvad J.C., Sun B.D., VArga J., Kocsubé S., DiJksterhuis J., Kim D.H., Hong S.-B., HOUBRAKEN J., SAMSON R.A. (2016): Aspergillus section Nidulantes (formerly Emericella): Polyphasic taxonomy, chemistry and biology. - Studies in Mycology 84: 1-118.

Chen A.J., Hubka V., Frisvad J.C., Houbraken J., Meijer M., VARGa J., Demirel R., JurJević Ž., KubÁtová A., SKLEnáŘ F., ZHOU Y.G., SAMSON R.A. (2017): Polyphasic taxonomy of Aspergillus section Aspergillus (formerly Eurotium), and its occurrence in indoor environments and food. Studies in Mycology 88: 37-135. 
DiJKsterhuis J., WÖSTEN H., eds. (2013): Development of Aspergillus niger. - Studies in Mycology 74: $1-85$.

Gargas A., Trest M.T., Christensen M., VOlK T.J., BleherT D.S. (2009): Geomyces destructans sp. nov. associated with bat white-nose syndrome. - Mycotaxon 108: 147-154.

GARRETT S.D. (1981): Soil fungi and soil fertility: an introduction to soil mycology, $2^{\text {nd }}$ ed. - Pergamon Press, Oxford.

GuARro J., GenÉ J., STChigel A.M., Figueras M.J. (2012): Atlas of soil Ascomycetes. - CBS Biodiversity Series 10, 486 p., Centraalbureau voor Schimmelcultures, Utrecht.

DE Hoog G.S. (2000): Atlas of clinical fungi, $2^{\text {nd }}$ ed. -1126 p., Centraalbureau voor Schimmelcultures, Utrecht / Universitat Rovira i Virgili, Reus.

Hubka V., Nováková A., Peterson S.W., Frisvad J., Sklenář F., Matsuzawa T., Kubátová A., KOLAŘÍK M. (2016): A reappraisal of Aspergillus section Nidulantes with descriptions of two new sterigmatocystin-producing species. - Plant Systematics and Evolution 302: 1267-1299.

Johnson L.J.A.N., Miller A.N., MCCleery R.A., MCClanahan R., Kath J.A., Lueschow S., PorrasALFARO A. (2013): Psychrophilic and psychrotolerant fungi on bats and the presence of Geomyces spp. on bat wings prior to the arrival of white nose syndrome. - Applied and Environmental Microbiology 79(18): 54-65.

Larcher G., Bouchara J.P., PAilley P., MontFort D., BÉGuin H., DE BiÈvre C., Chabasse D. (2003): Fungal biota associated with bats in western France. - Journal de Mycologie Médical 13: 29-34.

LORCH J.M., Muller L.K., Russell R.F., O’CONNOR M., LINDNER D.L., BlEHERT D.S. (2013): Distribution and environmental persistence of the causative agent of white-nose syndrome, Geomyces destructans, in bat hibernacula of the eastern United States. - Applied and Environmental Microbiology 79(4): 1293-1301.

MALLOCH D., HUBART J.-M. (1987): An undescribed species of Microascus from the Cave of Ramioul. - Canadian Journal of Botany 65(11): 2384-2388.

MARTínKOVÁ N. et al. (2010): Increasing incidence of Geomyces destructans fungus in bats from Czech Republic and Slovakia. - PLOS ONE 5(11): e13853.

NovÁKová A. (2009): Microscopic fungi from the Domica Cave system (Slovak Karst National Park, Slovakia). A review. - International Journal of Speleology 38: 71-82.

NovÁKovÁ A. (2012): Microscopic fungi associated with bats. - In: Kováč L', Uhrin M., L’uptáčik P., eds., $21^{\text {st }}$ International Conference on Subterranean Biology, $2^{\text {nd }}-7^{\text {th }}$ September 2012 , Košice, Slovakia. Abstract book, p. 78.

Nováková A., HubKa V., SAIZ-JIMEnez C., KOLAŘíK M. (2012): Aspergillus baeticus sp. nov. and Aspergillus thesauricus sp. nov., two species in section Usti from Spanish caves. - International Journal of Systematic and Evolutionary Microbiology 62: 2778-2785.

Nováková A., HubKa V., VAlinová Š., KOlAŘíK M., Hillebrand-VOICUlescu A.M. (2018): Cultivable microscopic fungi from an underground chemosynthesis-based ecosystem: a preliminary study. Folia Microbiologica 6: 1-13.

PARK J.H., PARK M.J. (2013): First report of black stem caused by Botryosporium longibrachiatum on sweet basil in Korea. - Plant Disease 97(3): 425.

Peterson S.W. (2008): Phylogenetic analysis of Aspergillus species using DNA sequences from four loci. - Mycologia 100: 205-226.

PuEChMAILle S.J. et al. (2011): Pan-European distribution of white-nose syndrome fungus (Geomyces destructans) not associated with mass mortality. - PLOS ONE 6(4): e19167.

SAMSON R.A., Cobus M., VISAGIE C.M., HoubRAKEn J., eds. (2014): Species diversity in Aspergillus, Penicillium and Talaromyces. - Studies in Mycology 78: 1-451.

SAMSON R.A., FRISVAD J.C. (2004): Penicillium subgenus Penicillium: new taxonomic schemes and mycotoxins and other extrolites. - Studies in Mycology 49: 1-174.

SAMSON R.A., Houbraken J. (2011): Phylogenetic and taxonomic studies on the genera Penicillium and Talaromyces. - Studies in Mycology 70: 1-183. 
SAMSON R.A., VARGA J. (2007): Aspergillus systematics in the genomic era. - Studies in Mycology 59: $1-206$.

SAMSON R.A., VARGA J., FRISVAD J.C. (2011): Taxonomic studies on the genus Aspergillus. - Studies in Mycology 69: 1-97.

Sandoval-Denis M., Guarro J., Cano-Lira J.F., Sutton D.A., Wiederhold N.P., DE Hoog G.S., ABвotT S.P., DECOCK C., SigLER L., GENÉ J. (2016): Phylogeny and taxonomic revision of Microascaceae with emphasis on synnematous fungi. - Studies in Mycology 83: 193-233.

SEIFERT K., Morgan-Jones G., GAMS W., KendRICK B. (2011): The genera of Hyphomycetes. - CBS Biodiversity Series 9, 997 p., Centraalbureau voor Schimmelcultures, Utrecht.

TRIBE H.T., WEBER R.W.S. (2001): Dead basil stems - a possible ecological niche for the hoar-frost fungus Botryosporium longibrachiatum. - Mycologist 15(4): 158-161.

VANDERWOLF K.J., MCAlPINE D.F., MALlOCH D., FORBES G.J. (2013a): Ectomycota associated with hibernating cave bats in eastern Canada prior to the emergence of white-nose syndrome. - Northeastern Naturalist 20(1): 115-130.

VANDERWOLF K.J., MALlOCH D., MCALPINE D.F., FoRBES G.J. (2013b): A world review of fungi, yeasts and slime molds in caves. - International Journal of Speleology 42(1): 77-96.

VANDERWOLF K.J., MALLOCH D., MCALPINE D.F. (2016): Fungi on white-nose infected bats (Myotis spp.) in Eastern Canada show no decline in diversity associated with Pseudogymnoascus destructans (Ascomycota: Pseudeurotiaceae). - International Journal of Speleology 45(1): 43-50.

VOYRON S., LAZZARI A., RICCUCCI M., CALVINI M., VARESE G.C. (2011): First mycological investigation on Italian bats. - Hystrix 22: 189-197.

Wibbelt G., Kurth A., Hellmann D., Weishaar M., Barlow A., Veith M., Pruger J., Gorfol T., Grosche L., Bontadina F., ZOPHEL U., SEIDL H.P., CRYAN P.M., BLEHERT D.S. (2010): White nose syndrome fungus (Geomyces destructans) in bats, Europe. - Emerging Infectious Diseases 16: $1237-1243$.

ZELLER L. (1966): Keratinophilic fungi from the Baradla cave in Aggtelek (Biospeleologica Hungarica, XXII). - Annals of the University of Sciences Budapest, Section Biology, 8: 375-388.

Zukal J., BANĎOUChOVÁ H., BARTONIČKa T., BERKová H., BRACK V., BRichta J., DOLINAY M., JAROŇ K.S., Kováčová V., KovaŘík M., Martínková N., OndráČEk K., ŘEHÁK Z., TURner G.G., PikUla J. (2014): White-nose syndrome fungus: a generalist pathogen of hibernating bats. - PLOS ONE 9: e97224. 